\title{
Analysis of Plume Effects on Sonic Boom Signature for Isolated Nozzle Configurations
}

\author{
Raymond S. Castner* \\ National Aeronautics and Space Administration, Glenn Research Center, Cleveland, Ohio 44135
}

\begin{abstract}
Computational fluid dynamics (CFD) analysis has been performed to study the plume effects on sonic boom signature for isolated nozzle configurations. The objectives of these analyses were to provide comparison to past work using modern CFD analysis tools, to investigate the differences of high aspect ratio nozzles to circular (axisymmetric) nozzles, and to report the effects of underexpanded nozzle operation on boom signature. CFD analysis was used to address the plume effects on sonic boom signature from a baseline exhaust nozzle. Near-field pressure signatures were collected for nozzle pressure ratios (NPRs) between 6 and 10. A computer code was used to extrapolate these signatures to a ground-observed sonic boom $\mathrm{N}$-wave. Trends show that there is a reduction in sonic boom $\mathrm{N}$-wave signature as NPR is increased from 6 to 10 . The performance curve for this supersonic nozzle is flat, so there is not a significant loss in thrust coefficient as the NPR is increased. As a result, this benefit could be realized without significant loss of performance. Analyses were also collected for a high aspect ratio nozzle based on the baseline design for comparison. Pressure signatures were collected for nozzle pressure ratios from 8 to 12. Signatures were nearly twice as strong for the two-dimensional case, and trends also show a reduction in sonic boom signature as NPR is increased from 8 to 12. As low boom designs are developed and improved, there will be a need for understanding the interaction between the aircraft boat tail shocks and the exhaust nozzle plume. These CFD analyses will provide a baseline study for future analysis efforts.
\end{abstract}

\begin{tabular}{lll} 
& & \multicolumn{1}{c}{$\begin{array}{c}\text { Nomenclature } \\
\mathrm{C}_{\mathrm{fg}}\end{array}$} \\
$\mathrm{NPR}$ & $=$ & computed thrust (from $\mathrm{CFD}) /$ ideal thrust \\
$P$ & $=$ & local static pressure, psia \\
$P_{t}$ & $=$ & total pressure in nozzle \\
$P_{\infty}$ & $=$ & free-stream static pressure \\
$\Delta P / P_{\infty}$ & $=$ & $\left(P-P_{\infty}\right) / P_{\infty}$ \\
$\Delta P$ & $=$ & $P-P_{\infty}$ \\
$x$ & $=$ & axial distance, in. \\
$D$ & $=$ & test nozzle diameter, in. \\
$x / D$ & $=$ & nondimensional axial distance from jet simulator nose cone
\end{tabular}

\section{Introduction}

Supersonic aircraft have operational restrictions over populated areas because of the disturbance caused by the $\checkmark$ sonic boom. Research is needed to enable the reduction of sonic boom for supersonic cruise over land. The sonic boom is caused by the coalescence of shock waves formed off the aircraft. Recent work has been performed to demonstrate reduction of the sonic boom N-wave for supersonic aircraft. Examples are the Supersonic Boom Demonstrator $^{1}$ and the Quiet Spike ${ }^{2}$ program. These studies reduce the magnitude of the N-wave at the nose of the airplane by shaping the aircraft. A sample N-wave sonic boom signature is shown in Fig. 1. Work is also needed to reduce the magnitude of the $\mathrm{N}$-wave generated by the aft airplane components, including effects of the exhaust nozzle plume.

*Aerospace Engineer, Inlet and Nozzle Branch, 21000 Brookpark Road, Cleveland, OH 44135, AIAA Member. 


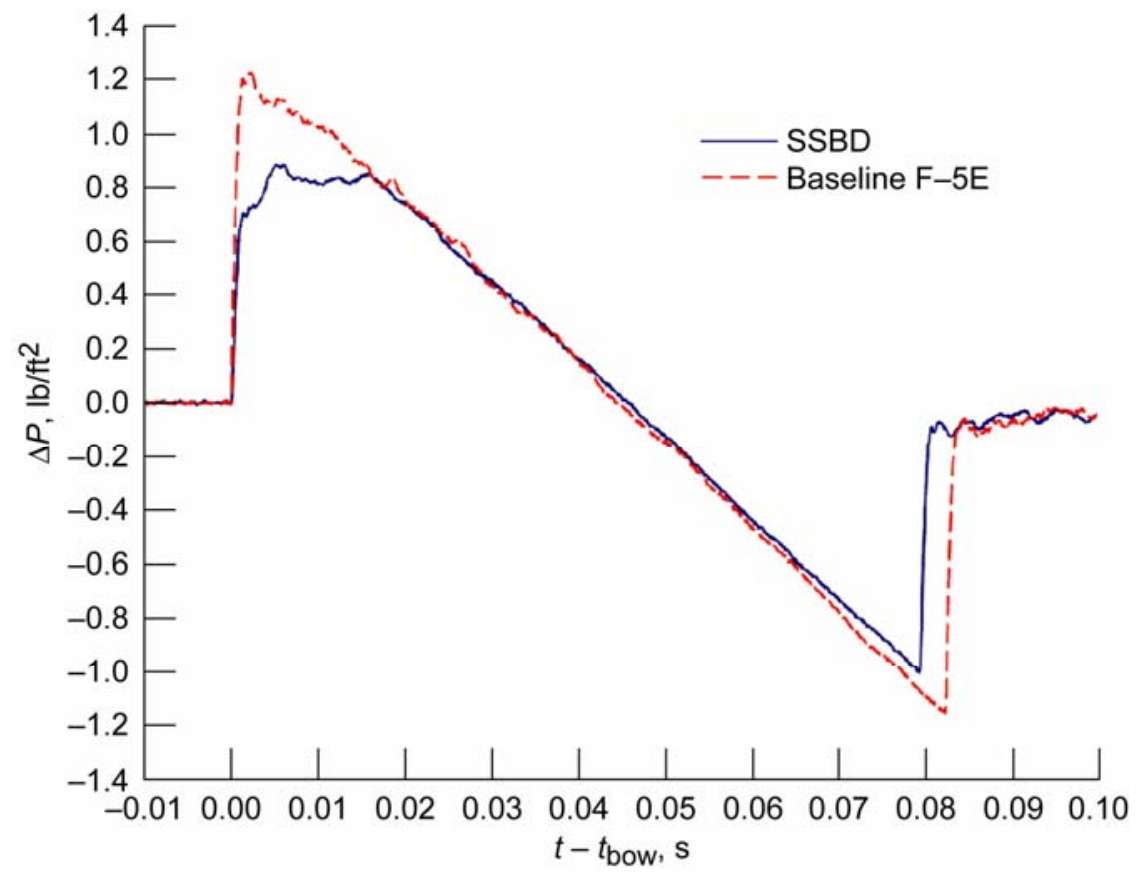

Fig. 1. Sample N-wave sonic boom signature. World's first ground-level shaped sonic boom recording in blue, baseline $\mathrm{F}-5 \mathrm{E} \mathrm{N}$-wave in red. Shaped sonic boom demonstration (SSBD) flight 9, August 27, 2003 (from ref. 1).

Past work has determined that the sonic boom N-wave signature is based on aircraft volume and lift. ${ }^{3}$ Also, previous studies examine the effect of various components, such as engine nacelles. ${ }^{4}$ More recent work has determined that the sonic boom signature can be extrapolated from the near-field pressures of an aircraft as measured near the vehicle. ${ }^{5}$ An analysis tool called "PCBoom" was developed using these theories to extrapolate pressures near the aircraft to an estimated ground-observed sonic boom. ${ }^{6}$

Previous work by Barger and Melson ${ }^{7}$ show that highly underexpanded nozzle plumes have a large effect on the sonic boom signature. Also in previous work by Putnam and Capone, ${ }^{8}$ a variety of nozzles were tested from a fully expanded mach 1.7 nozzle to a fully expanded mach 2.9 nozzle. Their study was conducted in a wind tunnel, where near-field pressure measurements were made at 1 nozzle diameter away from the test nozzle. Wind tunnel conditions were mach 2.2 at a simulated altitude of 50,000 ft. Inspection of their data demonstrated two trends, (1) near-field pressures are reduced when the nozzle is operated near its design point and (2) near-field pressures are reduced when the nozzle design point was matched to the flight conditions. Based on the trends from Putnam and Capone, a baseline nozzle was selected for a two-dimensional computational fluid dynamics (CFD) study. The nozzle configuration was selected to be operated close to the design point. For this study, "Nozzle 6" was selected as the baseline mach 2.0 nozzle in a simulated mach 2.2 flow field.

The objectives of this analysis were to provide comparison to past work using modern CFD analysis tools, to investigate the differences between high aspect ratio nozzles and circular (axisymmetric) nozzles, and to report the effects of underexpanded nozzle operation on boom signature.

Modern CFD tools were applied to the same nozzle configurations as tested by Putnam and Capone to provide a baseline for future nozzle plume studies. The CFD solutions were extrapolated to the far field to provide a baseline sonic boom N-wave. Additional CFD solutions were performed on a sample high aspect ratio nozzle configuration, using the baseline for comparison.

During the analysis, it was determined that overexpanded and underexpanded operation of the nozzle have an effect on the $\mathrm{N}$-wave boom signature. This trend was consistent for both the axisymmetric baseline and the high aspect ratio nozzle. This report summarizes the effect of an underexpanded nozzle plume on the $\mathrm{N}$-wave boom signature for an isolated nozzle configuration, and demonstrates the feasibility of reducing the magnitude of the sonic boom N-wave by controlling the nozzle plume interaction with the nozzle boat tail shock structure. 


\section{Analysis}

\section{A. Computational Domain and Grid}

\section{Baseline nozzle}

The baseline nozzle chosen from the experiment conducted by Putnam and Capone is shown in Fig. 2, and the wind tunnel model used for testing is in Fig. 3. The computational domain for the baseline nozzle, Nozzle 6, is shown in Figs. 4 and 5. The domain consists of the axisymmetric nozzle with geometry from NASA TN-D-5553, and had an external boat tail angle of 5 degrees; nozzle geometry is shown in Fig. 2 . The computational domain extends 18 nozzle diameters downstream of the nozzle exit, and 1.48 nozzle diameters above the nozzle outer wall. The length of the computational domain was extended beyond the experimental measurements in an attempt to capture additional effects and plume pressure signatures downstream of the nozzle exit. This grid was created with "Gridgen" software, and the first gridpoint off the nozzle wall was placed at wall coordinate distance, $y^{+}$, of one.

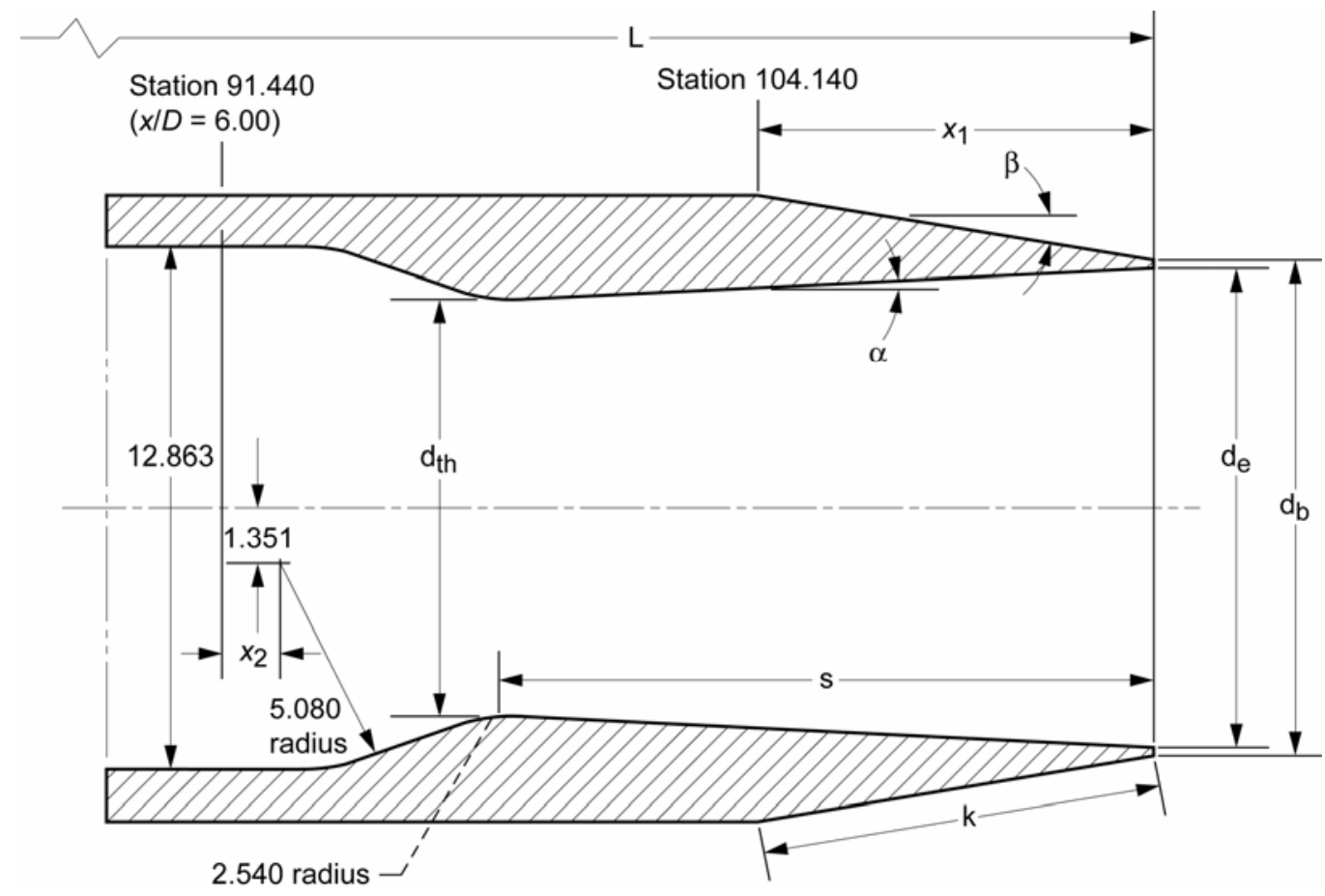

\begin{tabular}{|c|c|c|c|c|c|c|c|c|c|c|c|c|c|c|c|}
\hline Nozzle & $M_{j, d e s}$ & $\left(P_{t, j} / P_{\infty}\right)_{\text {des }}$ & $\begin{array}{c}\alpha, \\
\mathrm{deg}\end{array}$ & $\begin{array}{c}\beta, \\
\mathrm{deg}\end{array}$ & $x_{1}$ & $L$ & $k$ & $s$ & $d_{t h}$ & $d_{e}$ & $d_{b}$ & $A_{t h}$ & $A_{e}$ & $A_{e} / A_{t h}$ & $x_{2}$ \\
\hline 1 & 2.920 & 32.58 & 11.50 & 0 & 15.240 & 119.380 & 15.240 & 18.519 & 7.577 & 15.011 & 15.240 & 45.09 & 176.98 & 3.925 & 2.908 \\
\hline 2 & 2.272 & 11.97 & 7.28 & 0 & 15.240 & 119.380 & 15.240 & 18.747 & 10.264 & 15.011 & 15.240 & 82.75 & 176.98 & 2.139 & 4.224 \\
\hline 3 & 2.740 & 24.77 & 11.50 & 0 & 12.192 & 116.332 & 12.192 & 16.878 & 8.255 & 15.011 & 15.240 & 53.52 & 176.98 & 3.307 & 2.118 \\
\hline 4 & 2.523 & 17.72 & 11.50 & 0 & 9.144 & 113.284 & 9.144 & 14.883 & 9.144 & 15.011 & 15.240 & 65.66 & 176.98 & 2.695 & 2.118 \\
\hline 5 & 2.267 & 11.88 & 9.06 & 0 & 9.144 & 113.284 & 9.144 & 15.011 & 10.288 & 15.011 & 15.240 & 83.12 & 176.98 & 2.129 & 1.953 \\
\hline 6 & 2.024 & 8.12 & 6.04 & 5 & 9.109 & 113.249 & 9.144 & 15.105 & 10.223 & 13.417 & 13.646 & 82.08 & 141.39 & 1.722 & 1.778 \\
\hline 7 & 1.700 & 4.94 & 3.04 & 10 & 8.999 & 113.139 & 9.144 & 15.166 & 10.231 & 11.836 & 12.065 & 82.21 & 110.03 & 1.338 & 1.580 \\
\hline
\end{tabular}

Fig. 2. Nozzle configuration from NASA TN-D-5553. 


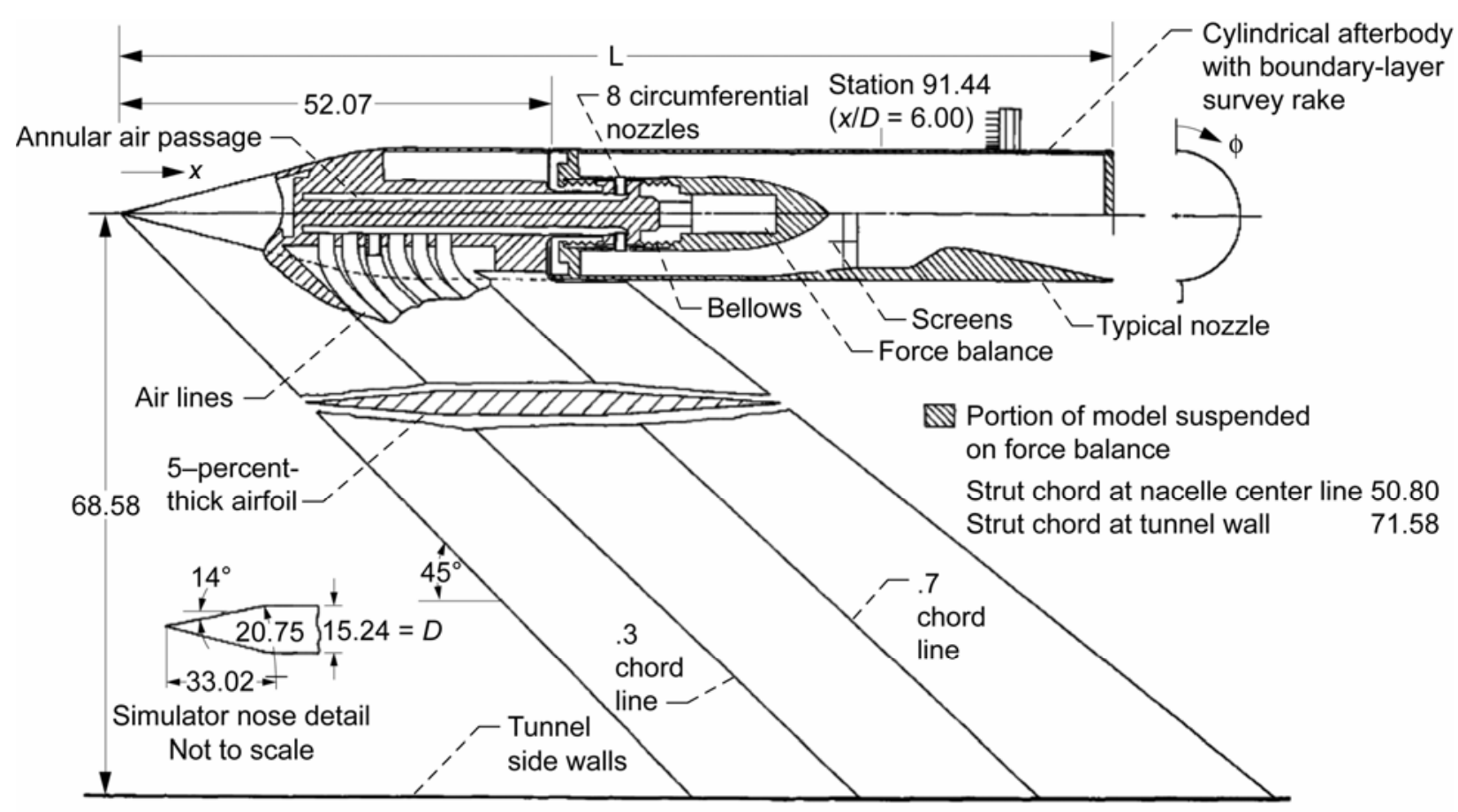

Fig. 3. Jet engine exhaust nozzle simulator from NASA TN-D-5553.

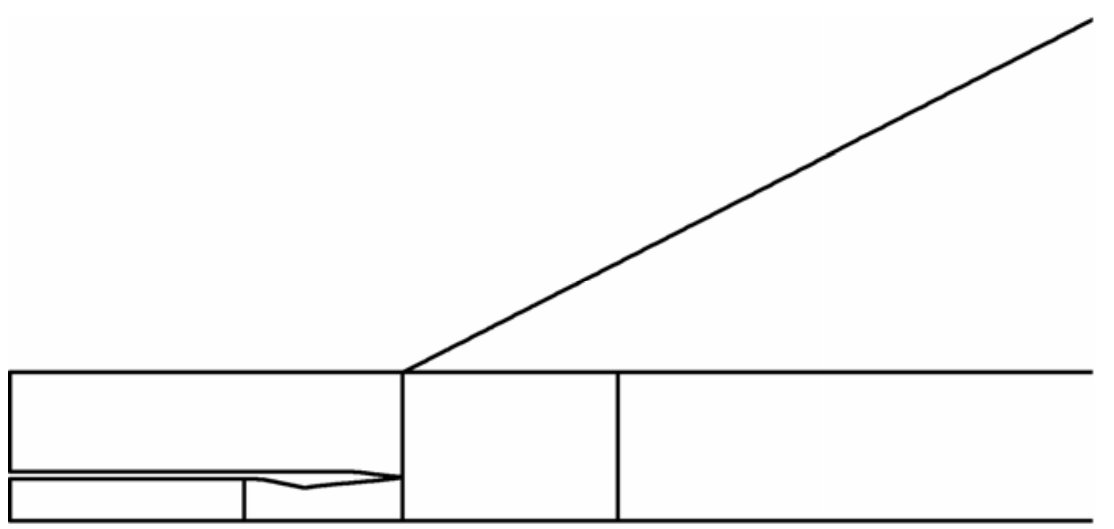

Fig. 4. Baseline Nozzle 6 grid closeup.

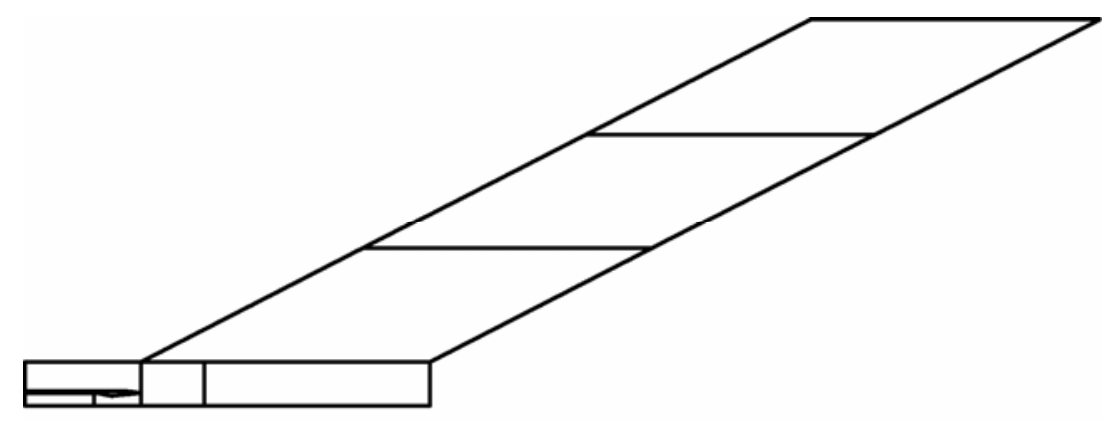

Fig. 5. Baseline Nozzle 6 grid layout closeup. 
The grid for Nozzle 6 is detailed in Figs. 4 and 5, and in Table 1. The overall grid was designed to be dense, especially in the free-stream zones, to capture the propagation of shocks off the nozzle geometry and plume. A grid density study validated the grid requirements, and is described later in this report. Based on the grid study, the baseline nozzle analysis used a two-dimensional grid of 511,299 gridpoints.

Table 1. Baseline Nozzle 6 grid summary.

\begin{tabular}{|c|c|c|c|c|}
\hline Zone & Name & $\mathrm{i}$ & $\mathrm{j}$ & Gridpoints \\
\hline 1 & Nozzle Inlet & 121 & 161 & 19481 \\
\hline 2 & Nozzle Exit & 419 & 161 & 67459 \\
\hline 3 & Free stream 1 & 207 & 103 & 21321 \\
\hline 4 & Free stream 2 & 111 & 293 & 32523 \\
\hline 5 & Free stream 3 & 201 & 293 & 58893 \\
\hline 6 & Free stream 4 & 311 & 333 & 103563 \\
\hline 7 & Free stream 5 & 311 & 333 & 103563 \\
\hline 8 & Free stream 6 & 311 & 336 & 104496 \\
\hline & & & Total & 511299 \\
\hline
\end{tabular}

\section{High aspect ratio nozzle}

A high aspect ratio slot nozzle configuration was modeled to investigate the utility of high aspect ratio nozzles for reduction of sonic boom signature. The grid was modified from the axisymmetric grid used for Nozzle 6 with the same grid density. The internal nozzle contours were modified using a method of characteristics code to design a mach 2.2 slot nozzle, with an aspect ratio of 8:1. To simplify the analysis, the CFD simulation was performed on a two-dimensional slice through this nozzle. Geometry for this nozzle was a simple expansion ramp design with a 2 -in. throat height, a 3.88-in. exit height, and an overall length of $18.02 \mathrm{in.}$

\section{B. Computational Algorithm}

\section{Wind-US}

Wind-US is a computational platform that numerically solves various sets of equations governing physical phenomena. ${ }^{9}$ The code supports the solution of the Euler and Navier-Stokes equations of fluid mechanics, along with supporting equation sets governing turbulent and chemically reacting flows. The current version of Wind-US is 2.0. Wind-US was used with the modified second-order Roe upwind scheme for stretched grids, implicit time stepping with a Courant-Friedrichs-Levy (CFL) number of 1.0, and the shear stress transport (SST) turbulence model. No grid sequencing was used. Boundary layer thickness was specified on the nozzle outer wall in the mach 2.2 free stream flow to match the boundary layer as measured in NASA TN-D-5553.

\section{Results}

1. Baseline nozzle

Results for near-field pressures, which will be used to compute sonic boom signature, are typically plotted as $\Delta P / P_{\infty}$. This is the primary input for the PCBoom code. Two computations of $\Delta P / P_{\infty}$ were performed for this study.

Both the current CFD results and the NASA TN-D-5553 wind tunnel results were performed at mach 2.2 and a simulated altitude of $50,000 \mathrm{ft}$. In the wind tunnel, near-field pressure measurements were made at 1 nozzle diameter away from the test nozzle. Figure 3 shows the wind tunnel model, where an $x / D$ of zero is the front of the nose cone. The first effort was to validate the CFD. Data was taken from NASA TN-D-5553 Nozzle 6, which was digitized from the report and displayed in Fig. 6. A CFD data set was obtained at a nozzle pressure ratio (NPR) of 8, which would provide data near the design point of this nozzle, and would match the experimental test conditions. Figure 7 shows contour plots of $\Delta P / P_{\infty}$ and mach number for the CFD simulation. For a comparison of CFD results to experimental results, a cut was made through the CFD grid, also at 1 nozzle diameter away from the test nozzle as was done in the experiment. Cut planes are also shown in Fig. 7.

The $\Delta P / P_{\infty}$ pressure signatures were compared to the experimental data. The full results from the CFD are shown in Fig. 8, and a subset for direct comparison is provided in Fig. 6. The CFD computed the first $\triangle P / P_{\infty}$ underpressure of -0.21 at an $x / D$ of 8.55 , followed by an overpressure of 0.11 at $x / D$ of 8.7 . This can be compared to the experimental data where the first $\Delta P / P_{\infty}$ underpressure was measured as -0.2 at $x / D$ of 8.6 and an overpressure of 0.1 at $x / D$ of 8.7. The difference in the maximum and the minimum pressures are 10 and 6 percent. Differences are attributed to the difficulty in surveying pressures in a supersonic wind tunnel. Problems can include effects from the 
wind tunnel model supports and the ambient pressure changes in the test section. ${ }^{10}$ Expansion waves from the wind tunnel or strut support can affect the initial expansion wave at the nozzle boat tail. CFD predicts a stronger expansion, which results in a stronger shock.

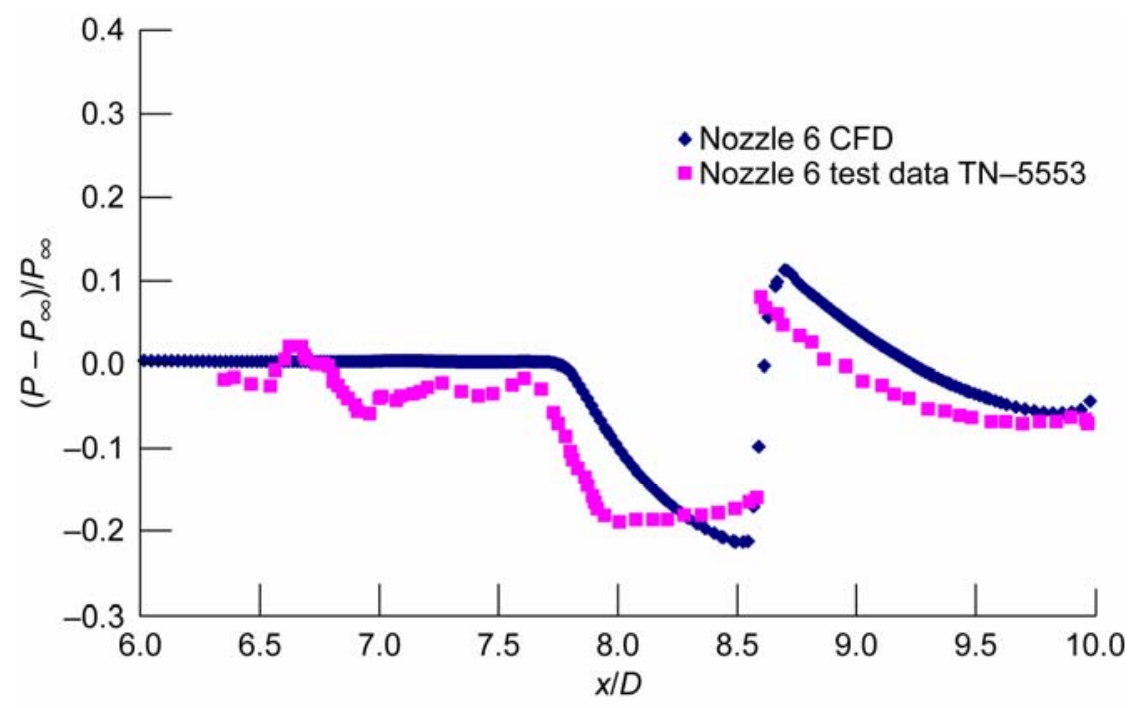

Fig. 6. Near-field pressure profile $\Delta P / P_{\infty}$ at 1 nozzle diameter from baseline Nozzle 6 axial positions $x / D$ from 6 to 10 comparisons to NASA TN-D-5553.
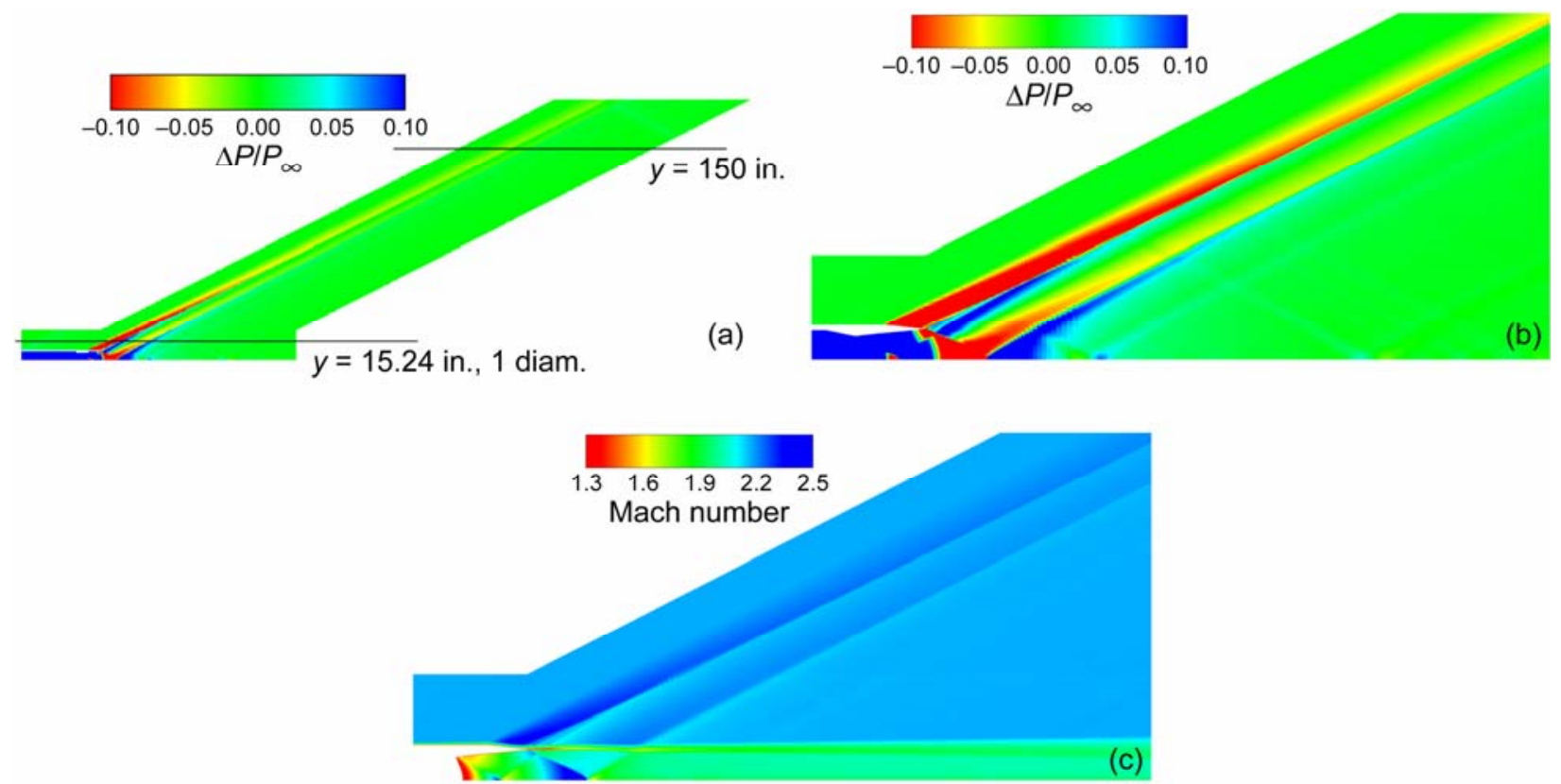

Fig. 7. (a) Baseline Nozzle $6 \Delta P / P_{\infty}$ for the design NPR 8 at mach 2.2. (b) Closeup of baseline Nozzle $6 \Delta P / P_{\infty}$ for the design NPR 8 at mach 2.2. (c) Closeup of baseline Nozzle 6 mach contours for NPR =8 and mach 2.2. 


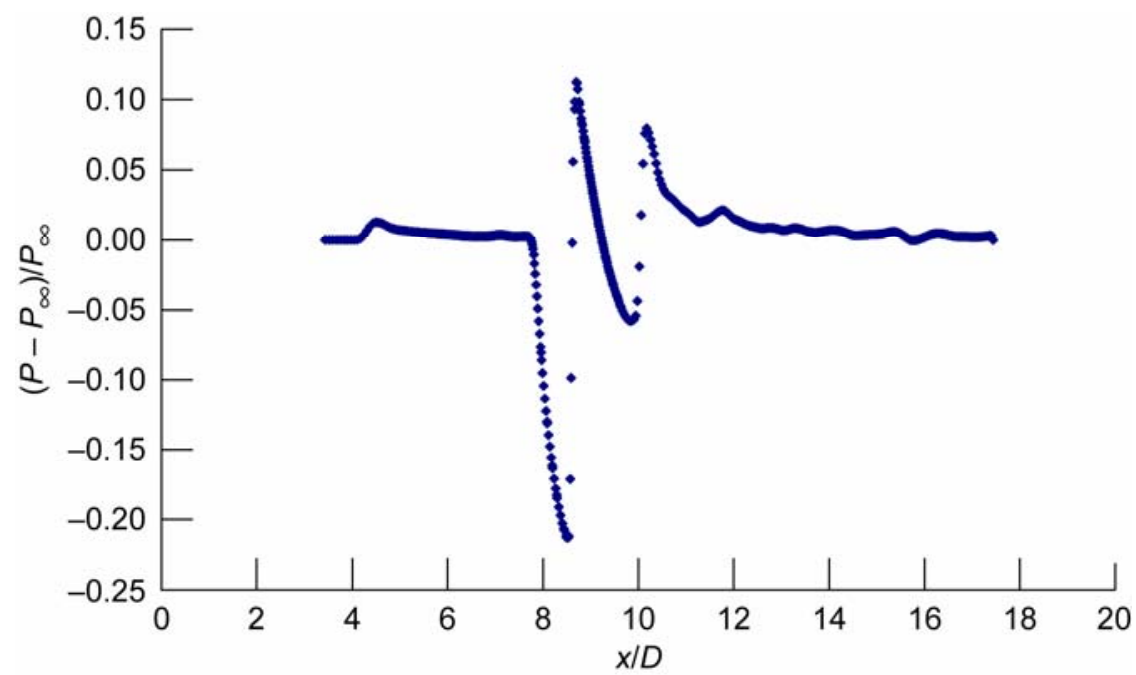

Fig. 8. Near-field pressure profile $\Delta P / P_{\infty}$ at 1 nozzle diameter from baseline Nozzle 6.

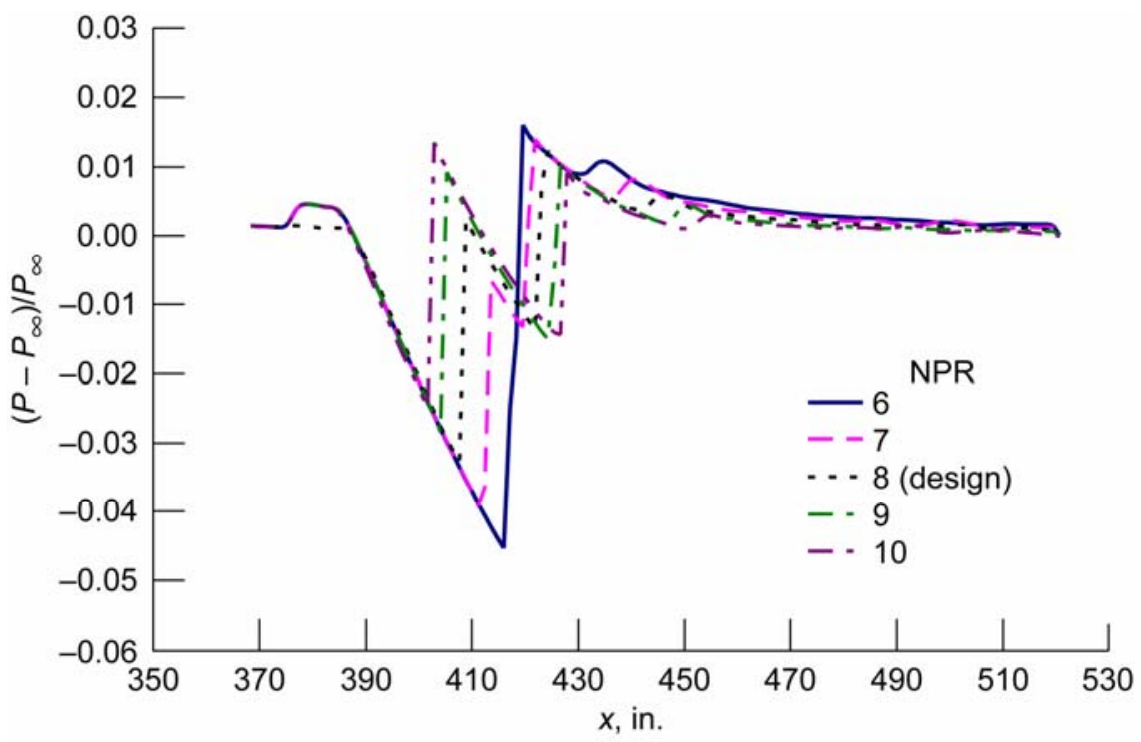

Fig. 9. Far-field pressure profiles $\Delta P / P_{\infty}$ at $y=150$ in. from nozzle centerline. Baseline Nozzle 6 NPR 6 to 10.

Figure 8 shows that beyond an $x / D$ of 10.2 , there was a second overpressure predicted by CFD analysis, which was not captured in any of the testing performed for NASA TN-D-5553. During testing, pressure surveys stopped at an $x / D$ of 10 .

Data was taken from the CFD solution to use in the PCBoom code to extrapolate to an estimated ground sonic boom pressure signature. PCBoom requires the user to provide a pressure signature far away from the aircraft or nozzle to consider the source as a point source. This need is balanced with the need to keep a CFD analysis grid to a reasonable size and to obtain adequate propagation of external shock waves. Some trial and error was required on grid size to obtain reasonable results; ground boom signatures extrapolated from a location that was too close to the nozzle produced erratic results.

A cut was made through the data at $150 \mathrm{in}$. from the nozzle centerline, or at 9.8 nozzle diameters, and this data is in Fig. 9. A series of nozzle pressure ratios were run, from 6 to 10, to develop a performance curve for this nozzle, and the $\Delta P / P_{\infty}$ for each of these conditions is plotted. From this plot, the trend shows peak $\Delta P / P_{\infty}$ underpressure is 
reduced as the NPR increases from 6 to 10. Increasing NPR increases the underexpansion in nozzle flow and causes the plume to expand, reducing the boat tail expansion wave and recompression shock, illustrated in Fig. 10.

The data at $150 \mathrm{in}$. was used as an input to a subroutine of PCBoom, called "foboomv." Flight conditions were $50,000 \mathrm{ft}$ at mach 2.2 for straight and level flight through a uniform atmosphere. The output is the sonic boom signature for all angles under the aircraft. This study used the signature at zero degrees, directly underneath the aircraft. In this case, there is no actual aircraft signature, so the signature is just from the nozzle and nozzle plume in simulated flight. Figure 11 shows the estimated sonic boom N-wave as perceived at ground level. The trend is similar from the pressure signatures in Fig. 9. The peak-to-peak strength of the computed sonic boom N-wave is reduced with increasing NPR.

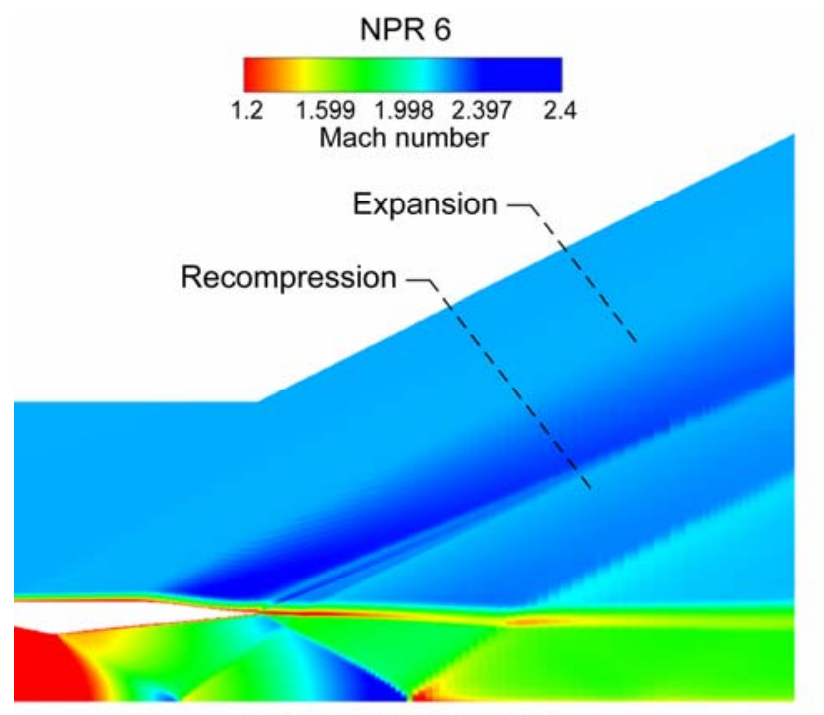

Slightly overexpanded

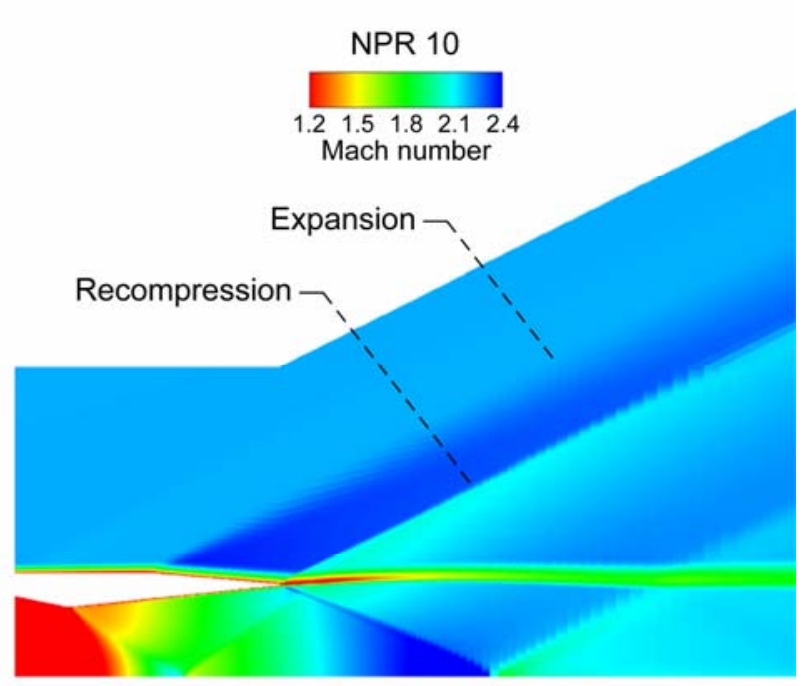

Slightly underexpanded

Fig. 10. Effect of nozzle operating conditions on the local shock waves. Baseline Nozzle 6 at NPR 6 and 10.

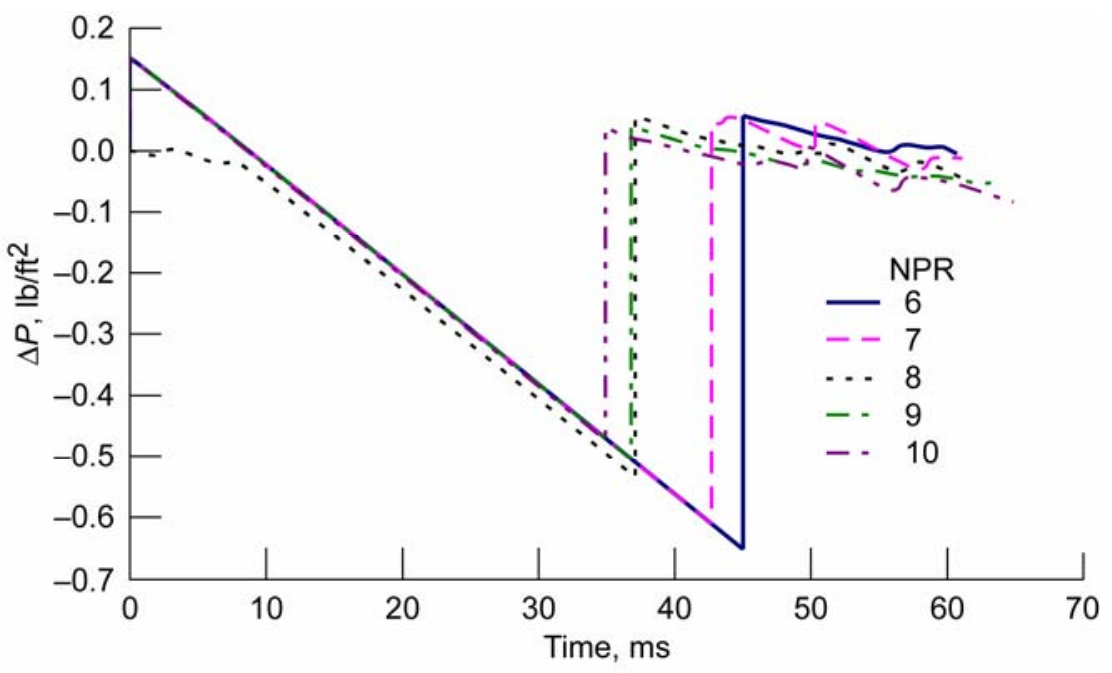

Fig. 11. Estimated sonic boom signature at ground through an ideal atmosphere. Baseline Nozzle 6 at NPR 6 to 10. 
The sonic boom signature for the design point at an NPR of 8 differs in the forward part of the N-wave boom signature. The data input and processing with PCBoom was the same for all cases, and the difference does not affect the overall trend.

\section{High aspect ratio nozzle}

Following the baseline analysis, a simplified two-dimensional CFD analysis was performed to demonstrate if high aspect ratio nozzle configurations would provide for a favorable distribution of near-field pressures in the nozzle and plume system, which would reduce sonic boom. If favorable, a high aspect ratio nozzle would enable a highly integrated configuration, as long slot nozzles could blend into a wing. Potential advantages include a lowprofile integration of the exhaust nozzle into a low boom vehicle concept. As a result, comparisons were done of a high aspect ratio nozzle to the baseline axisymmetric nozzle configuration. The high aspect ratio nozzle was designed using a method of characteristics code to match the exit area of the baseline nozzle. A high aspect area ratio was selected at 8:1. More aspect ratios would be analyzed if a favorable near-field pressure distribution was computed.

A two-dimensional nozzle was designed using a method of characteristics computational code. The nozzle was designed to have the same area as Nozzle 6 from the previous axisymmetric study, and an aspect ratio of 8:1 was chosen. The nozzle was designed for an NPR of 8 at mach 2.2, and the CFD simulation was simply a twodimensional simulation to study the far-field pressure and shock patterns. No end effects or three-dimensional effects were modeled for this study.

As before, a cut was made through the data at 150 in. from the nozzle centerline, and this data is in Fig. 12. A series of nozzle pressure ratios were run, from 8 to 12 , and the $d P / P$ for each of these conditions is plotted. The shock patterns from the two-dimensional nozzle were much stronger than the axisymmetric case. Figures 13 and 14 show the difference in expansion waves which are caused by the nozzle boat tail and the plume. As NPR is increased from 8 to 11, the plume expansion shock interacts with the boat tail expansion shock. This can be seen in the $\Delta P / P_{\infty}$ signatures in Fig. 12. As NPR is increased from 8 to 12 , the underpressure is changed from a negative value of -0.085 to -0.03 .

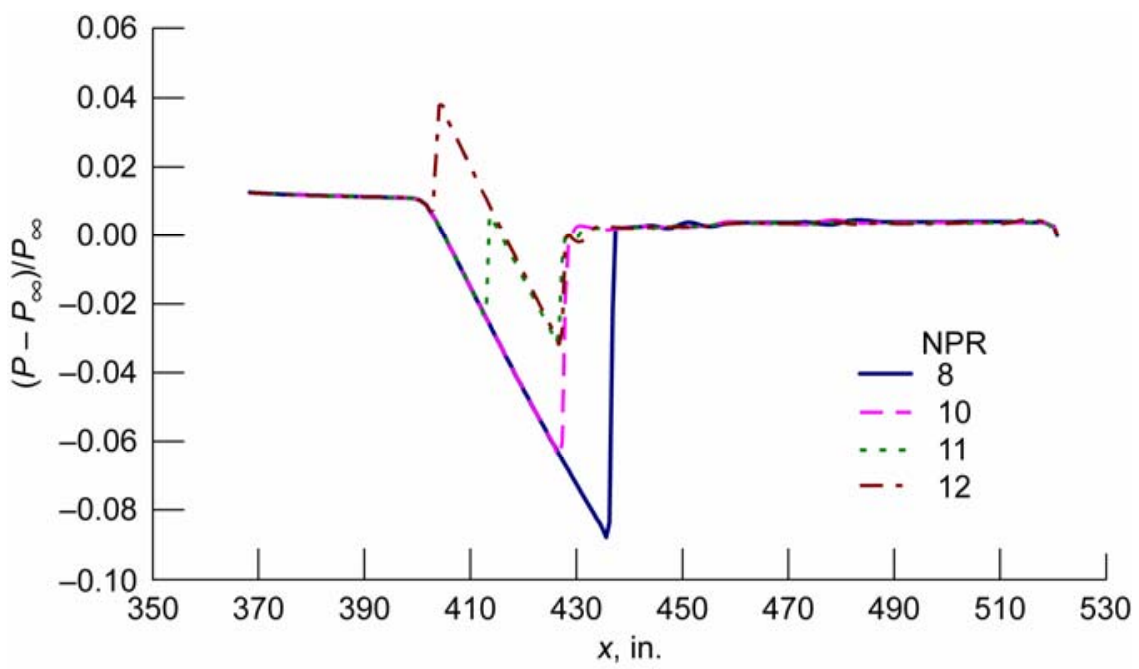

Fig. 12. Far-field pressure profiles $\Delta P / P_{\infty}$ at $y=150$ in. from nozzle centerline. Nozzle 6 slot nozzle NPR 8 to 12. 

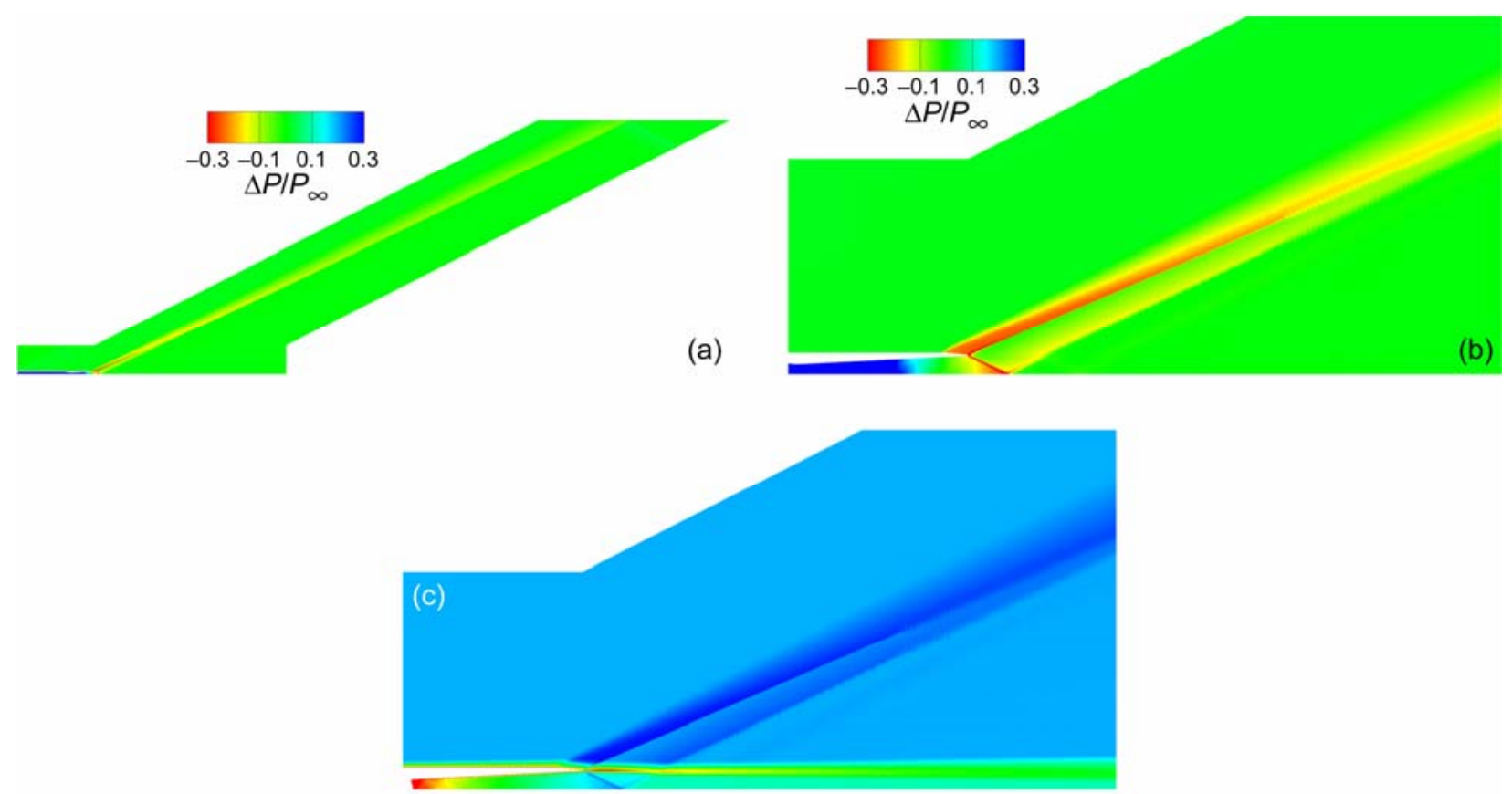

Fig. 13. (a) $\Delta P / P_{\infty}$ for Nozzle 6 slot nozzle configuration, design NPR 8. (b) Closeup of $\Delta P / P_{\infty}$ for Nozzle 6 slot nozzle configuration, NPR 8. (c) Closeup of mach number for Nozzle 6 slot nozzle configuration, NPR 8.

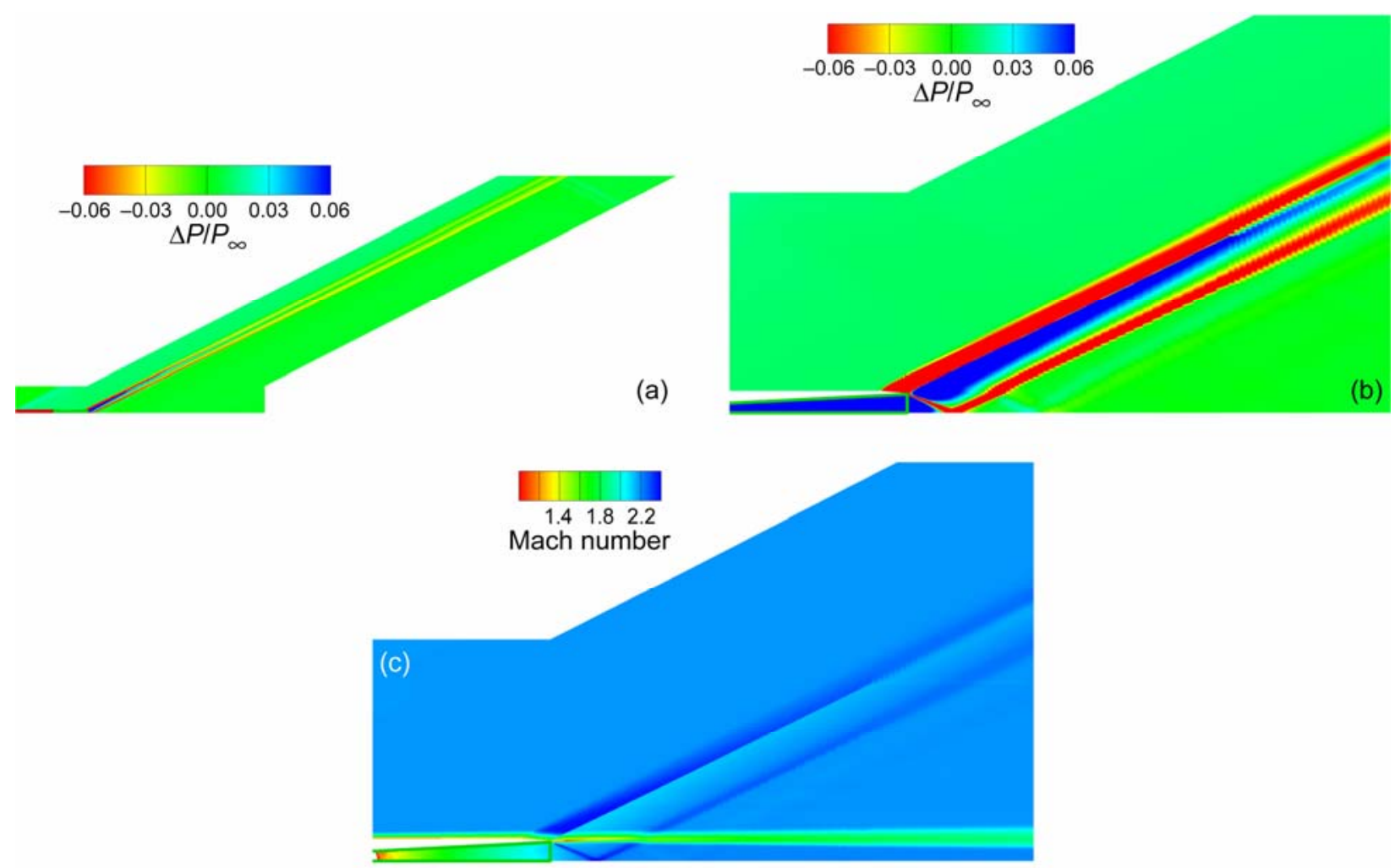

Fig. 14. (a) $\Delta P / P_{\infty}$ for Nozzle 6 slot nozzle configuration, NPR 11. (b) Closeup of $\Delta P / P_{\infty}$ for Nozzle 6 slot nozzle configuration, NPR 11. (c) Closeup of mach number for Nozzle 6 slot nozzle configuration, NPR 11. 
These pressure signatures show very strong $\Delta P / P_{\infty}$ signatures created by the two-dimensional geometry, and are nearly double that of the axisymmetric case. As a result, the PCBoom ground pressure signatures are not reported here, as the ground pressures were unreasonably high. A full three-dimensional simulation of this nozzle may produce more realistic ground pressure signatures. However, it seems reasonable to assess that the local expansion shocks generated by two-dimensional nozzles are locally stronger than that of an axisymmetric case. This result is consistent with the differences between shock structures created by a wedge and a cone. For low boom design, stronger shocks are undesirable. However, these results may still be beneficial in the study of highly integrated low boom aircraft and propulsion systems. Also, the two-dimensional solution used for this study may not accurately capture the three-dimensional effects of a high aspect ratio nozzle. Future small-scale wind tunnel testing will validate this result.

\section{Grid Studies}

A grid density study was performed on the baseline axisymmetric Nozzle 6 configuration. The grid study reduced the number of gridpoints for all zones by a factor of 2 and then a factor of 3 . The reduction of gridpoints by a factor of 2 had a measurable effect on the $\Delta P / P_{\infty}$ signature at $150 \mathrm{in.} \mathrm{from} \mathrm{the} \mathrm{nozzle} \mathrm{centerline,} \mathrm{reducing} \mathrm{the}$ magnitude of peak pressures by 10 percent (see Fig. 15). Further reduction to a factor of 3 was similar. Grid density was then increased by a factor of 1.4 , and results were nearly identical to the original baseline grid. As a result, all CFD cases kept the original dense grid at 511,299 gridpoints.

\section{Nozzle Boat Tail Angle}

The nozzle boat tail angle had an effect on the initial expansion shock wave from the nozzle. To study this effect, the baseline nozzle was modified to create a 2-degree boat tail angle. Figure 16 makes a direct comparison of nozzle boat tail angle on the boom signature for an NPR of 8, and shows the reduction in boom signature.

For the baseline Nozzle 6 , results for near-field pressures at 150 in. from the nozzle centerline are summarized in Fig. 17. Results are for NPRs from 7 to 9 , and are more difficult to interpret, as the signatures are hard to distinguish. To clarify differences, the estimated boom signature was computed and is shown in Fig. 18. Differences are noticeable between an NPR of 7 and 8. For NPR of 9, the boom signature becomes stronger. For the 2-degree boat tail angle, there is a narrower band of pressure ratios, between 7 and 8, where there is a benefit in adjusting the nozzle pressure ratio. Further study can determine an optimum configuration of boat tail angle and nozzle operating parameters.

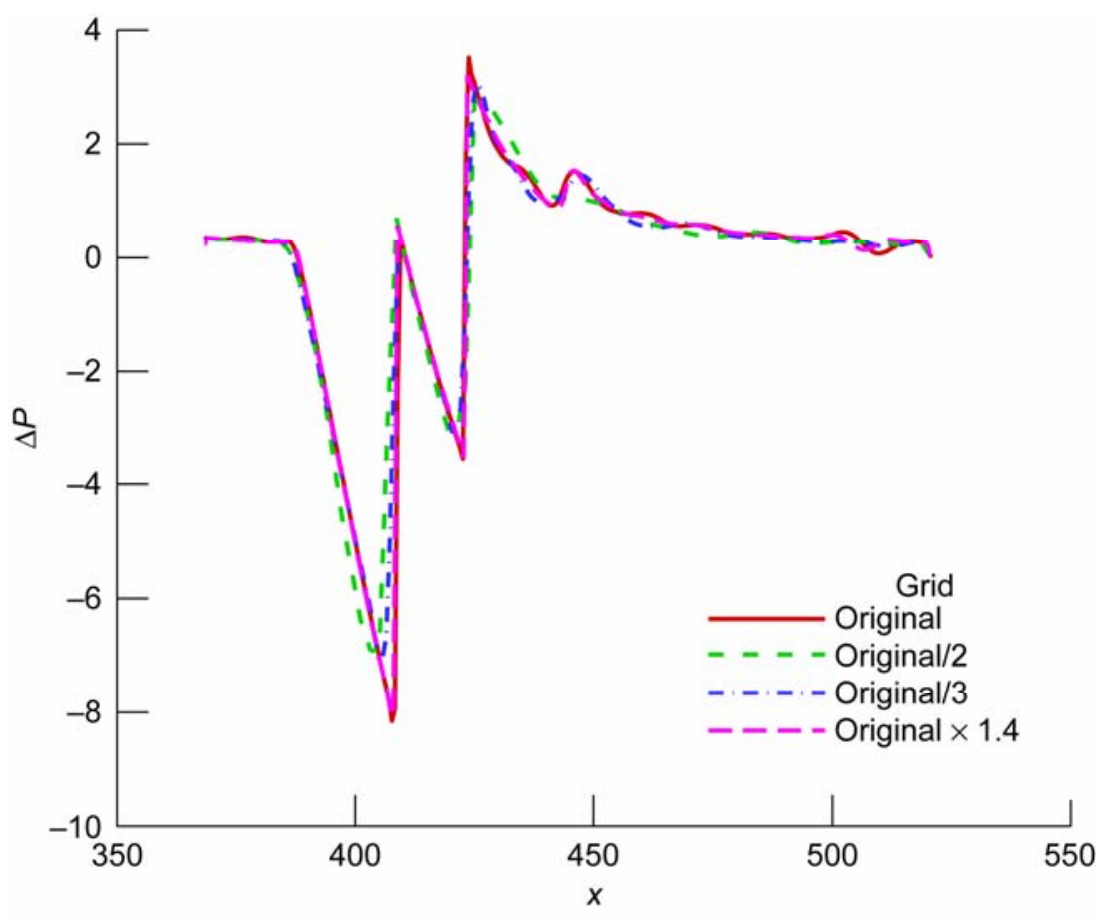

Fig. 15. Baseline Nozzle 6 grid study results. 


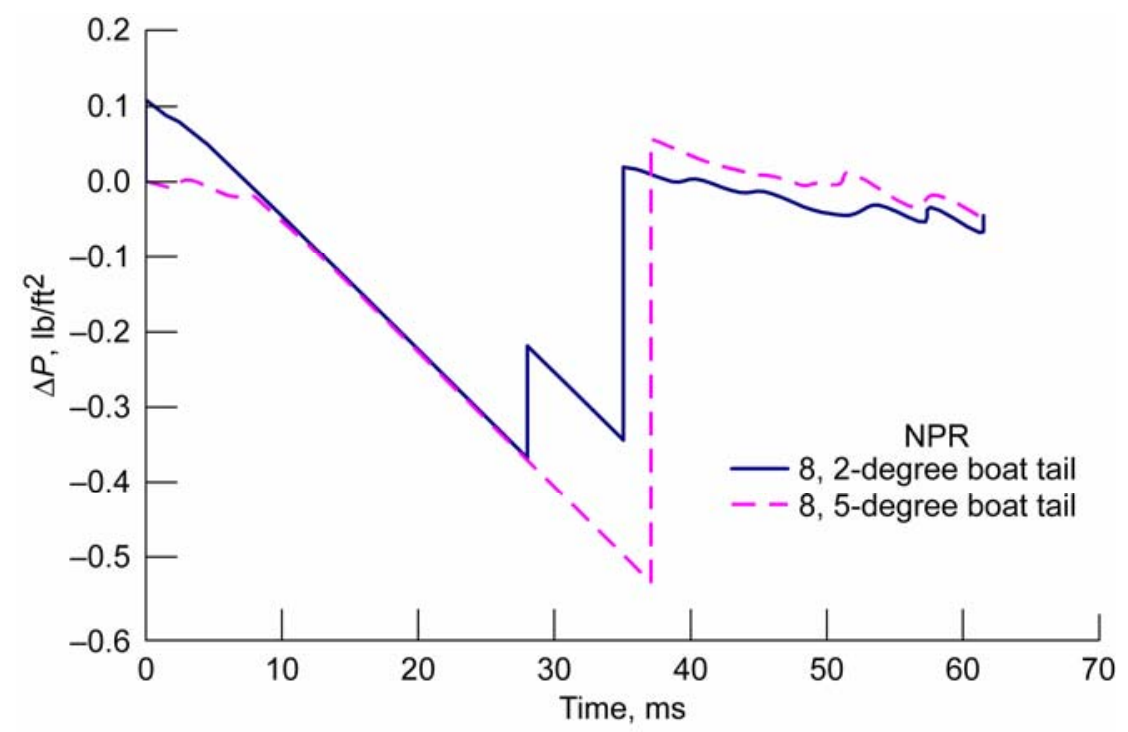

Fig. 16. Estimated sonic boom signature at ground through an ideal atmosphere, computed with PCBoom. Nozzle 6 comparison of 5-degree and modified 2-degree boat tail angle at NPR 8.

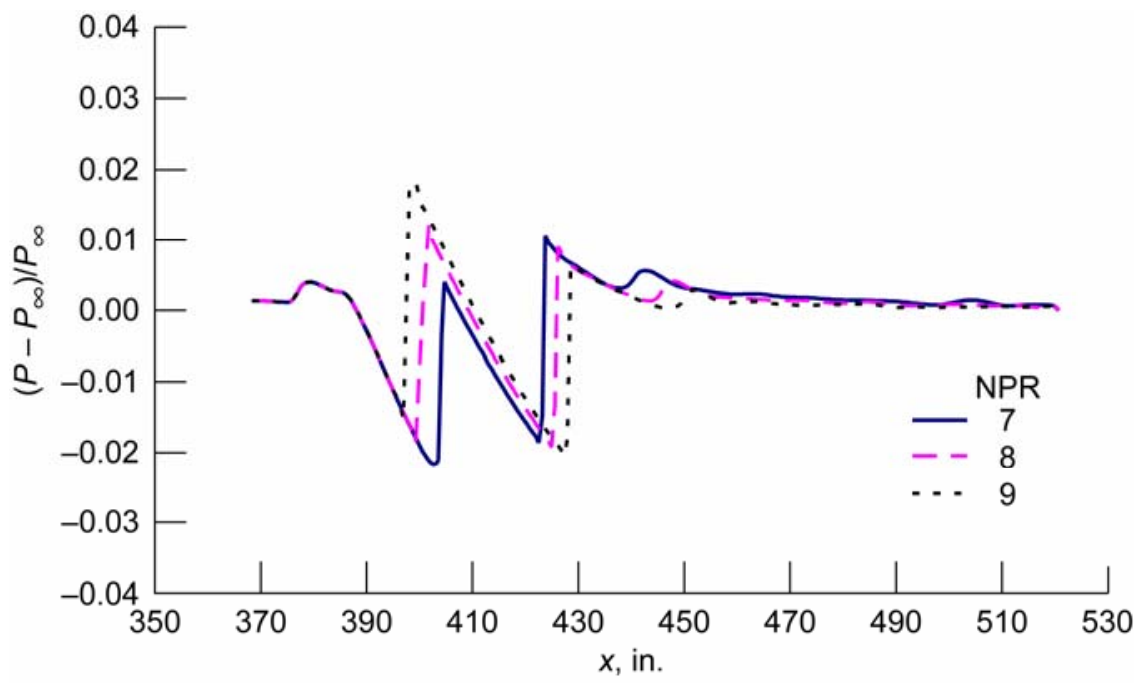

Fig. 17. Far-field pressure profiles $\Delta P / P_{\infty}$ at $y=150$ in. from nozzle centerline. Nozzle 6 with a modified 2-degree boat tail angle at NPR 7 to 9. 


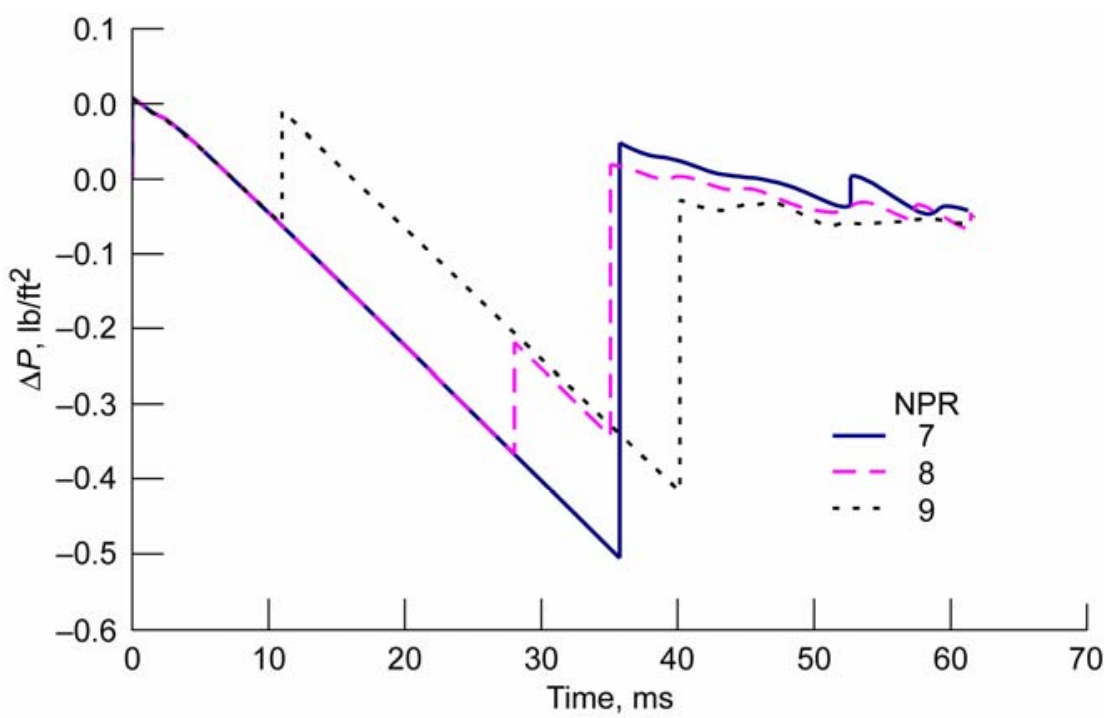

Fig. 18. Estimated sonic boom signature at ground through an ideal atmosphere, computed with PCBoom. Nozzle 6 with a modified 2-degree boat tail angle at NPR 7 to 9.

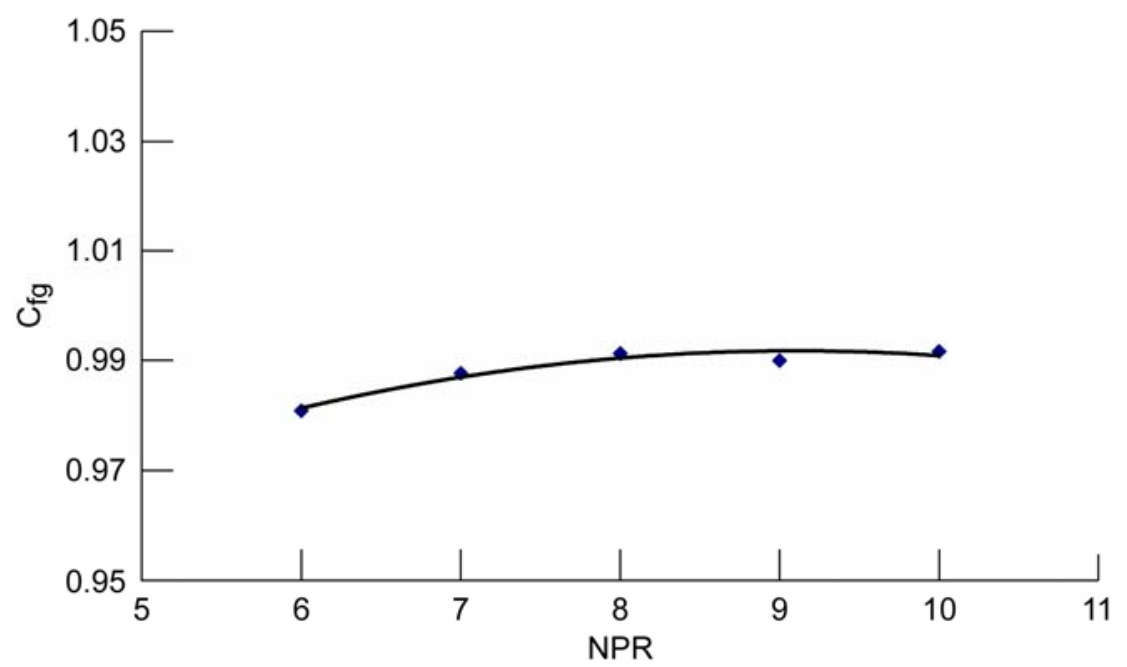

Fig. 19. Baseline Nozzle 6 performance curve.

\section{Conclusions}

CFD analysis was used to address the plume effects from isolated exhaust nozzles on sonic boom signature. The CFD analysis used Nozzle 6 from NASA TN-D-5553 as a baseline. Values of $\Delta P / P_{\infty}$ were computed for $x / D$ values less than 10 and at 1 nozzle diameter from the nozzle centerline, and agreement between the CFD analysis and the NASA TN-D-5553 experimental data for Nozzle 6 was acceptable. Results show that there was a second $\Delta P / P_{\infty}$ overpressure beyond an $x / D$ of 10 that was not captured in NASA TN-D-5553.

The $\Delta P / P_{\infty}$ pressure signatures at $150 \mathrm{in}$. from the nozzle centerline were collected for the baseline axisymmetric Nozzle 6 configuration. Pressure signatures were collected for nozzle pressure ratios between 6 and 10. PCBoom extrapolated these signatures to a ground-observed sonic boom N-wave. Trends show a reduction in sonic boom Nwave signature as NPR is increased from 6 to 10, as underexpanded nozzle operation reduces the boat tail expansion and recompression shock. Nozzle boat tail angle has an important effect on the reduction of sonic boom signature; further study is needed to optimize combinations of nozzle pressure ratio and boat tail angle. For the pressure ratios studied, the performance curve for this nozzle is flat (see Fig. 19), so there is no significant loss in thrust coefficient as the NPR is increased. As a result, this benefit could be realized without significant loss of performance. 
The $\Delta P / P_{\infty}$ pressure signatures at $150 \mathrm{in}$. from the nozzle centerline were also collected for a high aspect ratio nozzle based on the Nozzle 6 design for comparison. Pressure signatures were collected for nozzle pressure ratios from 8 to 12 . The $\Delta P / P_{\infty}$ signatures were nearly twice as strong for the two-dimensional case, and trends also show a reduction in sonic boom signature as NPR is increased from 8 to 12 .

As future low boom aircraft designs are developed and improved, there will be a need for improved understanding of the interaction between the aircraft boat tail shocks and the exhaust nozzle plume. These CFD analyses are intended to provide a baseline study for future analysis efforts. Future efforts will be needed to investigate plume interaction trends on an integrated aircraft and propulsion system problem.

\section{References}

${ }^{1}$ Graham, D., et al.: Aerodynamic Design of Shaped Sonic Boom Demonstration Aircraft. AIAA 2005-0009, 2005.

2.Freund, D., et al.: Quiet Spike Prototype Aerodynamic Characteristics From Flight Test. AIAA 2008-125, 2005.

${ }^{3}$ Mack, R.; and Kuhn, N.: Determination of Extrapolation Distance With Measured Pressure Signatures From Two LowBoom Models. NASA/TM-2004-213264, 2004.

${ }^{4}$ Mack, R.: Some Considerations on the Integration of Engine Nacelles Into Low-Boom Aircraft Concepts. High-Speed Research Sonic Boom. Vol. 2, pp. 221-235.

${ }^{5}$ Plotkin, K.; and Page, J.: Extrapolation of Sonic Boom Signatures From CFD Solutions. AIAA 2002-0922, 2002.

${ }^{6}$ Plotkin, K.; and Grandi, F.: Computer Models for Sonic Boom Analysis: PCBoom4, CABoom, BooMap, CORBoom. Wyle Report WR 02-11, June 2002.

${ }^{7}$ Barger, Raymond L.; and Melson, N. Duane: Comparison of Jet Plume Shape Predictions and Plume Influence on Sonic Boom Signature. NASA TP-3172, 1992.

${ }^{8}$ Putnam, Lawrence A.; and Capone, Francis J.: Experimental Determination of Equivalent Solid Bodies to Represent Jets Exhausting Into a Mach 2.20 External Stream. NASA TN D-5553, 1969.

${ }^{9}$ Bush, R.H.; Power, G.D.; and C.E. Towne: WIND: The Production Flow Solver of the NPARC Alliance, AIAA Paper 98-0935, 1998.

${ }^{10}$ Morgenstern, J.M.: Wind Tunnel Testing of a Sonic Boom Minimized Tail-Braced Wing Transport Configuration, AIAA-2004-4536, 2004. 